\title{
KEANEKARAGAMAN DAN KOMPOSISI VEGETASI POHON \\ PADA KAWASAN AIR TERJUN TAKAPALA DAN LANNA DI KABUPATEN GOWA SULAWESI SELATAN
}

\section{DIVERSITY AND COMPOSITION OF TREE VEGETATION IN LANNA AND TAKAPALA WATER FALL AREA, GOWA REGENCY, SOUTH SULAWESI}

Tri Sutrisna, Muh. Ruslan Umar, Sri Suhadiyah, Slamet Santosa

\author{
Departemen Biologi, Fakultas Matematika Dan Ilmu Pengetahuan Alam, \\ Universitas Hasanuddin, Makassar
}

Email :riznarahman28@gmail.com

\begin{abstract}
Abstrak
Keanekaragaman dan komposisi vegetasi pohon di kawasan air terjun Lanna dan Takapala, Kabupaten Gowa, Sulawesi Selatan sudah diteliti pada bulan Desember 2016 dan januari 2017. Penelitian ini bertujuan untuk mengetahui keanekaragaman dan komposisi vegetasi pohon yang tumbuh pada kawasan air terjun Takapala dan Lanna di Kabupaten Gowa. Metode yang digunakan yaitu metode Point Centered Quarter (PCQ) dan metode analisis komunitas mencakup indeks keanekaragaman, keseragaman, dominansi . Hasil identifikasi di kawasan air terjun Lanna terdapat 24 species, 19 familia, sedangkan di kawasan air terjun Takapala terdapat 25 species, 17 familia. Hasil penelitian indek keanekaragaman jenis di kawasan air terjun Lanna dan Takapala berkisar 2.785- 2.965 (katagori sedang). Indeks keseragaman komunitas di kawasan Air Terjun Lanna dan Takapala berkisar antara 1.700 - 1.805 (katagori tinggi). Indeks dominansi di kawasan Air Terjun Lanna dan Takapala berkisar antara 0.053-0.075 (katagori rendah). Penelitian ini menyimpulkan bahwa jenis tumbuhan pembentuk vegetasi hutan di air terjun Lanna dengan di air terjun Takapala relatif berbeda.
\end{abstract}

Kata kunci: Keanekaragaman, keseragaman , dominansi dan komposisi pohon

\begin{abstract}
The diversity and composition of tree vegetation in the Lanna and Takapala waterfall areas, Gowa regency, South Sulawesi have been studied in December 2016 and January 2017. This study aims to determine the diversity and composition of tree vegetation that grows in the waterfall Takapala and Lanna in Gowa. The method used is Point Centered Quarter (PCQ) method and community analysis method include index of diversity, uniformity, dominance. The results of identification in Lanna waterfall area there are 24 species, 19 families, while in the waterfall Takapala there are 25 species, 17 families. The results of the species diversity index in the Lanna and Takapala waterfalls ranged from 2,785 to 2,965 (moderate category). The uniformity index of community in Lanna and Takapala Falls ranges from 1,700 - 1,805 (high category). The dominant index in Lanna and Takapala Falls ranges from 0.053-0.075 (low category). This research concludes that plant species of forest vegetation in Lanna waterfall with waterfall Takapala relatively different
\end{abstract}

Keywords: Diversity, uniformity, dominance and tree composition 


\section{Pendahuluan}

Indonesia merupakan salah satu negara beriklim tropis yang menjadi pusat megabiodiversity tertinggi kedua di dunia. Salah satu pulau besar di Indonesia yang memiliki keanekaragaman hayati yang tinggi, unik dan bersifat endemik adalah pulau Sulawesi. Alasan utama yang menyebabkan pulau Sulawesi memiliki flora dan fauna yang unik dan bersifat endemik adalah pulau Sulawesi tidak pernah menyatu secara utuh dengan benua Asia dan Australia yang mengapitnya. Walaupun spesies-spesies flora dan fauna yang hidup di Pulau Sulawesi sebagian berasal dari benua Asia dan Australia, tetapi tidak sedikit pula spesies yang hanya dijumpai hidup di pulau Sulawesi dan tidak dijumpai di habitat alami wilayah lainnya. Pulau Sulawesi termasuk dalam region peralihan antara flora dan fauna Asia dan Australia, yang biasa dikenal dengan flora dan fauna region Wallaceae (Hamidum dan Dewi, 2013). Flora Sulawesi merupakan salah satu kekayaan alam yang cukup unik dan menarik. Keunikan ini tak terlepas dari pengaruh dua daratan benua yang dalam sejarahnya telah ikut membentuk pulau yang dikenal sebagai areal peralihan flora fauna. Jumlah jenis tumbuhan diperkirakan sekitar 5000 di Sulawesi dan terdapat 57 jenis tumbuhan yang hidup endemik di beberapa tempat diantaranya di propinsi Gorontalo ada 16 jenis, Sulawesi Utara 13 jenis, Sulawesi Tenggara 10 jenis, Sulawesi Tengah 9 jenis dan di Sulawesi Selatan 9 jenis (Butar butar, R. R. dan Soemarno, 2013).

Hutan memiliki peranan sangat penting bagi kehidupan makhluk hidup yaitu sebagai sumber daya alam. Keanekaragaman tumbuhan yang terdapat pada hutan berfungsi sebagai bahan pangan, sandang, papan, dan yang juga penting adalah penghasil oksigen dan pereduksi karbondioksida dari atmosfir, serta habitat fauna dan flora (Soerianegara, 1978). Keanekragaman tumbuhan di suatu kawasan hutan relatif bervariasi dan sangat bergantung pada faktor iklim dan edafit. Keanekaragaman tumbuhan terutama pohon yang memiliki nilai ekonomis yang penting bagi masyarakat. Namun pada kenyataannya masyarakat yang berada disekitar kawasan, terkadang melakukan penebangan pohon secara sembarangan dan tidak terkendali untuk berbagai kepentingan ekonomi. Hal ini menyebabkan terjadinya perubahan struktur dan komposisi vegetasi, yang berdampak terganggunya fungsi ekosistem hutan tersebut (Endawati, 2005). Berdasarkan uraian diatas, maka dilakukan penelitian keanekaragaman dan struktur jenis pohon di kawasan air Terjun Takapala dan Lanna, Kabupaten Gowa, Sulawesi Selatan.

\section{Metode Penelitian}

Penelitian ini dilakukan pada bulan Desember 2016 dan Januari 2017 di kawasan air terjun Lanna dan Takapala, kabupaten Gowa. Alat yang digunakan dalam penelitian ini adalah peta lokasi air terjun, alat tulis menulis, kamera, kompas, hand counter, Global Positioning System (GPS), meteran panjang 5 dan $100 \mathrm{~m}$, tali rapia, dan buku data, buku taksonomi tumbuhan. Bahan yang digunakan adalah alkohol $70 \%$, kertas koran, kertas label, selotip dan plastik sampel. Metode yang digunakan yaitu observasi dengan tujuan mendapatkan gambaran umum tentang lokasi penelitian dan keanekaragaman vegetasi pohon yang dijadikan dasar untuk penentuan lokasi dan titik sampling di kawasan air terjun Lanna dan Takapala. Sedangkan pengumpulan data vegetasi pohon dilakukan dengan menggunakan metode Kuarter (Metode point centered quarter (PCQ)), Gambar 1. Analisis data yaitu index keanekaragaman, keseragaman dan dominansi menggunakan rumus berikut. 


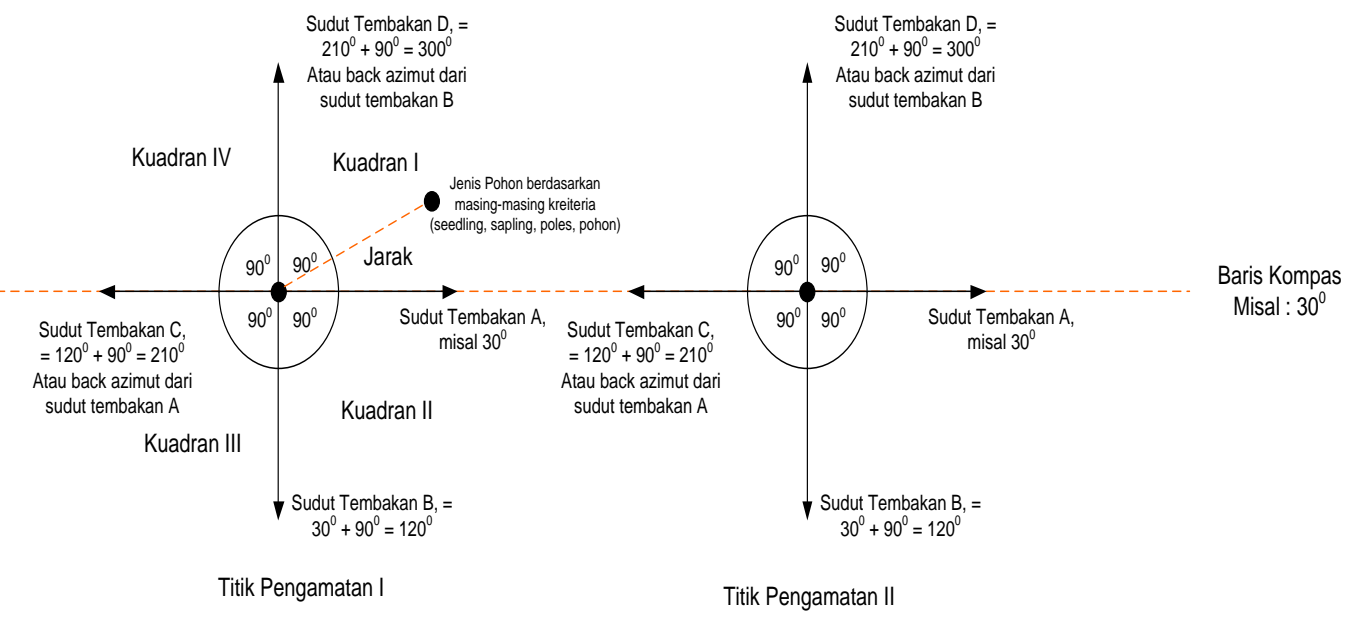

Gambar 1.Model Metode Point Centered Quarter (PCQ).

\section{Indeks Keanekaragaman}

Indeks keanekaragaman yang digunakan adalah Indeks keanekaragaman dari Shannon- Wiener (Shannon's index) (Odum, 1993) dengan rumus sebagai berikut:

Keterangan:

$$
H^{\prime}=-\sum(p i \ln p i)
$$

$H^{\prime}$ : Indeks keanekaragaman Shannon,

pi : (ni/n)

$n i$ : jumlah individu suatu jenis ke- $i$

$n$ : total jumlah individu dalam PU.

Kriteria kisaran nilai indeks keanekaragaman adalah sebagai berikut:

$\mathrm{H}<1$ : Keanekaragaman jenis rendah

$1<\mathrm{H}^{\top}<3$ :Keanekaragaman jenis sedang

$\mathrm{H}>3$ : Keanekaragaman jenis tinggi

\section{Indeks Keseragaman}

Keseragaman dihitung dengan menggunakan rumus Eveness Index yaitu:

$$
E=\frac{H^{\prime}}{\ln (S)}
$$

Keterangan:

$E$ : Indeks kemerataan untuk jenis

$H^{\prime}$ : Indeks Keanekaragaman

$S$ : jumlah jenis yang dijumpai dalam PU. 
Kriteria kisaran nilai indeks keseragaman adalah sebagai berikut:

$\mathrm{E}<0,3 \quad$ : Keseragaman populasi kecil

$0,3<\mathrm{E}<0,6$ :Keseragaman populasi sedang

$\mathrm{E}>0,6 \quad$ :Keseragaman populasi tinggi

\section{Indeks Dominansi}

Indeks dominansi dihitung berdasarkan rumus indeks dominansi dari Simpson (Odum, 1993) yaitu:

$$
C=\sum_{i=1}^{S}(p i)^{2} \mathrm{pi}=\mathrm{ni} / \mathrm{N}
$$

Keterangan :

C : Indeks Dominansi

pi : ni/N

ni : Jumlah individu ke-i ;

$\mathrm{N}$ : Jumlah total individu

Kriteria kisaran nilai ilndeks dominansi adalah sebagai berikut:

$0,01<C \leq 0,30$ : Dominasi rendah

$0,31<C \leq 0,60$ : Dominansi sedang

$0,61<C \leq 1,00$ : Dominansi tinggi

Semakin besar nilai indeks dominansi (C), maka semakin besar pula kecenderungan adanya jenis tertentu yang mendominasi.

\section{Hasil dan Pembahasan}

\section{Hasil}

Hasil pengamatan dan identifikasi jenis tumbuhan yang berhabitus pohon di kawasan air terjun Lanna dan Takapala, diperoleh 36 species tumbuhan dari 25 familia (Tabel 1).

Tabel 1. Jenis vegetasi pohon yang tumbuh di kawasan air terjun Lanna dan Takapala, Kabupaten Gowa

\begin{tabular}{|l|l|l|c|c|}
\hline \multirow{2}{*}{ Famili } & \multirow{2}{*}{ Nama Lokal } & \multicolumn{2}{c|}{ Species } & \multicolumn{2}{c|}{$\begin{array}{c}\text { Kawasan Air } \\
\text { Terjun }\end{array}$} \\
\cline { 4 - 5 } & & & Lanna & Takapala \\
\hline Anacardinaceae & Kayu jawa & $\begin{array}{l}\text { Lannea coromandelica } \\
\text { (Hooet) Merr. }\end{array}$ & $\sqrt{ }$ & $\sqrt{ }$ \\
\hline Anacardinaceae & Mangga & Mangifera indica L. & $\sqrt{ }$ & $\sqrt{ }$ \\
\hline Anacardinaceae & Jambu monyet & Anacardium occidentale L. & $\sqrt{ }$ & - \\
\hline Apocynaceae & Pulai & Alstonia scolaris R. Br. & $\sqrt{ }$ & $\sqrt{ }$ \\
\hline Bombacaceae & Kapuk randu & Ceiba pentandra Gaertn. & $\sqrt{ }$ & $\sqrt{ }$ \\
\hline Caesalpiniaceae & Johar & Cassia siamea Lam. & $\sqrt{ }$ & - \\
\hline
\end{tabular}




\begin{tabular}{|c|c|c|c|c|}
\hline Caesalpiniaceae & Flamboyan & Delonix regia Raf. & $\sqrt{ }$ & - \\
\hline Caesalpiniaceae & Kassia & $\begin{array}{l}\text { Cassia surattensis Burm. } \\
\text { F. }\end{array}$ & - & $\sqrt{ }$ \\
\hline Casuarinaceae & Cemara gunung & Casuarina equisetifolia L. & $\sqrt{ }$ & - \\
\hline Celastraceae & 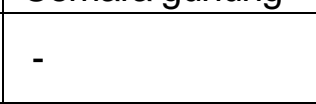 & $\begin{array}{l}\text { Salacia macrantha } \\
\text { A.C.Sm. }\end{array}$ & $\sqrt{ }$ & - \\
\hline Euphorbiaceae & Kemiri & $\begin{array}{l}\text { Aleurites moluccana (L) } \\
\text { Wild. }\end{array}$ & $\sqrt{ }$ & - \\
\hline Fabaceae & Ki Hujan & Samanea saman Merr. & $\sqrt{ }$ & $\sqrt{ }$ \\
\hline Fabaceae & Gamal & Glyricidia sepium Jacq. & - & $\sqrt{ }$ \\
\hline Flacourtiaceae & Lobi-Iobi & Flacourtia inermis Roxb. & - & $\sqrt{ }$ \\
\hline Lauraceae & Alpukat & Persea americana Mill. & - & $\sqrt{ }$ \\
\hline Lythraceae & Bungur & Lagerstroemia speciosa L. & $\sqrt{ }$ & - \\
\hline Malvaceae & Waru & Hibiscus tiliaceus L. & - & $\sqrt{ }$ \\
\hline Meliaceae & Mahoni & $\begin{array}{l}\text { Swietenia macrophylla } \\
\text { King. }\end{array}$ & $\sqrt{ }$ & - \\
\hline Mimosaceae & Akasia & Acacia auriculiformis A.Cunn. & $\sqrt{ }$ & - \\
\hline Moraceae & Beringin & Ficus benjamina L. & $\sqrt{ }$ & $\sqrt{ }$ \\
\hline Moraceae & Nangka & $\begin{array}{l}\text { Artocarpus heterophyllus } \\
\text { Lam. }\end{array}$ & - & $\sqrt{ }$ \\
\hline Moraceae & Sukun & Artocarpus communis Forst. & - & $\sqrt{ }$ \\
\hline Myrtaceae & Jambu air & Zyzygium aque Burm $\mathrm{F}$. & $\sqrt{ }$ & - \\
\hline Myrtaceae & Jambu biji & Psidium guajava L. & - & $\sqrt{ }$ \\
\hline Palmae/Aracaceae & Kelapa & Cocos nucifera L. & - & $\sqrt{ }$ \\
\hline Papilionaceae & Angsana & Pterocarpus indicus Will. & $\sqrt{ }$ & $\sqrt{ }$ \\
\hline Papilionaceae & Pohon Kupu-kupu & Bauhinia purpurea L. & $\sqrt{ }$ & $\sqrt{ }$ \\
\hline Pinaceae & Pinus & Pinus merkusii Jungh. & $\sqrt{ }$ & $\sqrt{ }$ \\
\hline Poaceae & Bambu & Bambusasp. & $\sqrt{ }$ & $\sqrt{ }$ \\
\hline Rubiaceae & Kopi & $\begin{array}{l}\text { Coffea canephora var } \\
\text { robusta }\end{array}$ & $\sqrt{ }$ & $\sqrt{ }$ \\
\hline Rubiaceae & Mengkudu & Morinda citrifolia L. & - & $\sqrt{ }$ \\
\hline Rutaceae & Jeruk puruk & Citrus aurantifolia Swingle. & - & $\sqrt{ }$ \\
\hline Rutaceae & Jeruk Bali & $\begin{array}{l}\text { Citrus maxima (Burm. F) } \\
\text { Merr. }\end{array}$ & - & $\sqrt{ }$ \\
\hline Sterculiaceae & Coklat & Theobroma cacao L. & - & $\sqrt{ }$ \\
\hline Symplocaceae & - & $\begin{array}{l}\text { Symplocos tinctoria (L.) } \\
\text { L'Her. }\end{array}$ & $\sqrt{ }$ & $\sqrt{ }$ \\
\hline Verbenaceae & Jati & Tectonia grandisLinn. f. & $\sqrt{ }$ & - \\
\hline \multicolumn{2}{|c|}{ Jumlah species } & 36 & 24 & 25 \\
\hline
\end{tabular}

Berdasarkan pada Tabel 1, menunjukkan kawasan air terjun Lanna terdapat 24 jenis pohon, dan pada lokasi air terjun Takapala terdapat 25 jenis pohon. Di Kawasan air terjun Lanna terdapat 11 jenis pohon yang tidak dijumpai di kawasan air terjun Takapala, sedangkan di kawasan air terjun Takapala terdapat 13 jenis pohon yang tidak dijumpai di kawasan air terjun Lanna, dan hanya terdapat 10 jenis pohon yang sama jenisnya di jumpai di kedua kawasan tersebut. Perbedaan ini dimungkinkan terjadi karena adanya perbedaan letak kawasan dari permukaan air laut, dan intensifnya penggunaan kawasan oleh masyarakat untuk keperluan perkebunan dan pertanian. 
Hasil analisis komunitas yaitu Indeks kenakeragaman, Indeks Keseragaman, dan Indeks Dominansi) vegetasi pohon yang tumbuh di kawasan air terjun Lanna dan Takapala disajikan pada Tabel 2 .

Tabel 2. Hasil analisis komunitas vegetasi pohon yang tumbuh di kawasan air terjun Lanna dan Takapala.

\begin{tabular}{|c|c|c|c|c|c|c|c|c|}
\hline \multirow{2}{*}{$\begin{array}{l}\text { Parameter } \\
\text { Analisis } \\
\text { Komunitas }\end{array}$} & \multicolumn{2}{|c|}{ Lanna } & \multirow{2}{*}{$\begin{array}{c}\mathrm{Re} \\
\text { rata }\end{array}$} & \multirow{2}{*}{$\begin{array}{c}\text { Kriteri } \\
\mathbf{a}\end{array}$} & \multicolumn{2}{|c|}{ Takapala } & \multirow[b]{2}{*}{ Rerata } & \multirow[b]{2}{*}{ Kriteria } \\
\hline & 1 & 2 & & & 1 & 2 & & \\
\hline $\begin{array}{l}\text { Indeks Keanekaga- } \\
\text { raman }(\text { Shannon- } \\
\text { Wiener }(\mathrm{H}))\end{array}$ & 2.95 & 2.62 & 2.785 & Sedang & 2.88 & 3.05 & 2.965 & Sedang \\
\hline $\begin{array}{l}\text { Indeks Keseragaman } \\
\text { (Eveness Index (E)) }\end{array}$ & 1.84 & 1.56 & 1.7 & Tinggi & 1.83 & 1.78 & 1.805 & Tinggi \\
\hline $\begin{array}{l}\text { Indeks Dominansi } \\
\text { (Simpson (Id)) }\end{array}$ & 0.054 & 0.096 & 0.075 & Rendah & 0.055 & 0.051 & 0.053 & Rendah \\
\hline
\end{tabular}

Indeks keanekaragaman vegetasi pohon yang tumbuh di kawasan air terjun Lanna berkisar 2.62-2.95 , sedangkan pada kawasan air terjun Takapala 2.88-3.05. Indeks keseragaman vegetasi pohon pada kawasan air terjun Lanna berkisar antara 1,84-1,56. Sedangkan pada kawasan air terjun Takapala nilai indeks keseragaman vegetasi pohon berkisar antara $1,78-1,83$. Nilai indeks dominansi vegetasi pohon tertinggi pada kawasan air terjun Lanna berkisar antara 0,054 - 0,096.Sedangkan nilai indeks dominansi vegetasi pohon pada kawasan air terjun Takapala berkisar 0,051-0,055.

\section{Pembahasan}

Vegetasi pepohonan sangat berperan dalam perlindungan tanah, pencegah erosi dan banjir, peredam polusi, menjaga keseimbangan iklim global dan sebagai sumber plasma nutfah. Jenis vegetasi pohon yang menyusun komunitas pada kawasan air terjun Takapala dan Lanna relatif berbeda.

Keanekaragaman suatu komunitas sangat bergantung pada jumlah jenis dan jumlah individu yang terdapat pada komunitas (Muhadiono, 2001). Keanekaragaman jenis suatu komunitas akan tinggi jika komunitas tersebut disusun oleh banyak jenis dan tidak ada species yang mendominasi. Sebaliknya, jika suatu komunitas memiliki nilai keanekaragaman jenis yang rendah, maka komunitas tersebut disusun oleh sedikit jenis dan ada species yang dominan (Indriyanto, 2006). Nilai indeks keanekaragaman ( $\mathrm{H}^{\prime}$ ) pada vegetasi pohon pada kawasan air terjun Lanna adalah 2.785 lebih rendah dibandingkan dengan pada kawasan air terjun Takapala yaitu 2.965. Hal ini berarti walaupun jumlah jenis yang terdapat di kedua kawasan tersebut relatif sama, tetapi terdapat beberapa jenis pohon yang memiliki kecenderungan untuk dominan di masing masing kawasan tersebut, walaupun tingkat dominansinya relatif masih rendah.

Nilai indeks keseragaman kawasan air terjun Lanna adalah 1,700, lebih rendah dibandingkan dengan dikawasan air terjun Takapala yaitu 1,805. Menurut Manurung dan Nirawati, (2016). jika nilai indeks keseragaman rendah, maka keseragaman species dalam komunitas kurang, artinya jumlah individu setiap jenis relatif sangat berbeda, sehingga ada kecenderungan didominasi oleh species tertentu. Sebaliknya, semakin besar nilai indeks keseragaman menunjukkan bahwa jumlah individu setiap jenis relatif merata, dan tidak ada jenis tertentu yang bersifat dominan. Berdasarkan hasil nilai indeks dominansi komunitas di kawasan air terjun Lanna adalah 0,075, lebih tinggi dibandingkan dengan indeks dominansi 
komunitas di kawasan air terjun Takapala yaitu 0,053. Nilai indeks dominansi dikedua air terjun menunjukkan kriteria rendah. Artinya di kedua air terjun tersebut, jumlah jenis dan jumlah setiap jenis vegetasi pohon cenderung merata, sehingga di kedua kawasan tidak ada species yang betul-betul mendominasi. Kondisi tersebut menunjukkan bahwa komunitas pohon dan ekologinya masih dalam keadaan stabil.

\section{Kesimpulan}

Penelitian ini menyimpulkan bahwa kawasan air terjun Lanna mempunyai komposisi vegetasi yaitu 19 familia dan 24 species, sedangkan kawasan air terjun Takapala terdapat 17 familia dan 25 species. Hasil analisis vegetasi dan komunitas menunjukkan keanekaragaman jenis di kedua kawasan penelitian termasuk kriteria sedang, tingkat keseragaman komunitas tergolong tinggi dan tidak ada jenis pohon yang dominan.

\section{Daftar Pustaka}

Butar butar, R..R. dan Soemarno, 2013. Pengaruh Aktivitas Wisatawan Terhadap Keanekaragaman Tumbuhan Di Sulawesi. Diakses Desember 2016.

Endarwati. 2005. Keanekaragaman Hayati dan Konservasinya di Indonesia. Diakses Januari 2017.

Hamidun, M. S., Dewi Wahyuni K., 2013. Struktur, Komposisi, dan Pola Distribusi Vegetasi pada Kawasan Hutan Lindung dan Hutan produksi terbatas. Universitas Negeri Gorontalo. Gorontalo.

Indiryanto, 2005. Ekologi Hutan. Penerbit Bumi Aksara. Jakarta.

Mahadiono, 2001. Ekologi Vegetasi. Laboratorium Ekologi. Institut Pertanian Bogor. Bogor.

Manurung, B., Nira Wati, 2016. Kajian Ekologi Tumbuhan Liana di Hutan Primer Taman Nasional Gunung Leuser Resort Sei Betung Kecamatan Besitang Kabupaten Langkat, Sumatera Utara.Program Studi Biologi, Universitas Negeri Medan. Medan

Odum, E. P., 1993. Dasar-Dasar Ekologi.. . Terjemahan Tjahjono Saminga. Penerbit Gajah Mada Press.. Yogyakarta.

Soerianegara, 1978. Ekologi Hutan Indonesia. Departemen Manajement Hutan. Fakultas Kehutanan. IPB. Bogor. 